\title{
PARA UM ATLAS PLURIDIMENSIONAL: PESQUISAS E PESOUISADORES
}

\author{
Vanderci de Andrade AGUILERA* \\ Fabiane Cristina ALTINO **
}

- RESUMO: Este artigo propõe apresentar à comunidade científica um balanço das atividades do Projeto Atlas Linguístico do Brasil (ALiB) no que tange à formação de novos pesquisadores e, ao mesmo tempo, demonstrar o que a equipe do Comitê Central produziu na década deste início de século. Para isso, dividiu-se o texto em quatro seções: (i) a constituição da equipe de investigadores que trata da composição do Comitê Nacional e das atribuições de cada um de seus componentes; (ii) a produção discente em projetos de Iniciação Científica, desenvolvidos nas várias regionais do ALiB; (iii) a produção dos discentes da pós-graduação lato e stricto sensu sob a orientação dos diretores científicos e (iv) a produção dos coordenadores e diretores científicos. Os resultados apontam para a diversidade de enfoques teórico-metodológicos na abordagem de fenômenos de variação no nível da fonética, do léxico e da morfologia, entre outros, e indicam a possibilidade de associar alguns aspectos da variação linguística registrada pelo ALiB à proposta de Nascentes (1953).

- PALAVRAS-CHAVE: Atlas linguístico do Brasil. Composição do Comitê Nacional. Produção científica. Divisão dialetal do Brasil.

\section{Apresentação}

A inovação no campo da Geolinguística atual, iniciada há cerca de duas décadas por Thun (2000), diz respeito à importância e à necessidade de associar dados diastráticos, diagenéricos, diageracionais, diarreferenciais e diamésicos aos dados diatópicos da Geolinguística iniciada por Wenker e Gilliéron, no final do século XIX.

Nessa perspectiva, o Atlas Linguístico do Brasil (ALiB), projeto em andamento, nacional e interinstitucional, agrega preceitos da Sociolinguística Variacionista à sua proposta de descrever a língua portuguesa falada no Brasil a partir de uma visão diatópica. Dessa forma, em se tratando de um atlas dessa envergadura,

\footnotetext{
* UEL - Universidade Estadual de Londrina. Departamento de Letras Vernáculas e Clássicas. Londrina - Paraná - Brasil. 86051-980 - vanderci@uel.br

** UEL - Universidade Estadual de Londrina. Departamento de Letras Vernáculas e Clássicas. Londrina - Paraná -Brasil. 86051-980 - fabiane_altino@uol.com.br
} 
isto é, que se propõe mapear a diversidade do português falado em um país cujo território abrange mais de $8.500 .000 \mathrm{~km}^{2}$, o ALiB não poderia ser um projeto nem individual nem de curta duração. Na realidade, acredita-se que o material já coletado e aquele que está para ser coletado servirão de objeto de estudo para várias gerações de pesquisadores.

Sem perder de vista a necessidade de preparar novos pesquisadores para dar continuidade à proposta iniciada em 1996, durante o Seminário Nacional de Geolinguística, o Comitê Nacional que dirige o ALiB, conseguiu, ao longo desses 15 anos, aliar a experiência dos veteranos ao vigor e dinamismo dos mais jovens de tal sorte que contabiliza como resultado parcial do projeto uma gama diversificada de produtos. Sobre eles pretende-se discorrer com o objetivo de apresentar à comunidade científica um balanço das atividades do Projeto ALiB no que tange à formação de novos pesquisadores e, ao mesmo tempo, demonstrar o que a equipe do Comitê Central produziu na década deste início de século. Para isso, estruturou-se o texto em quatro seções: 1. a constituição da equipe de investigadores; 2. a produção no nível da Iniciação Científica; 3. a produção no nível da pós-graduação lato e stricto sensu e 4. a produção dos coordenadores e diretores científicos.

\section{A constituição da equipe}

No lançamento do Projeto ALiB, durante o Seminário Caminhos e Perspectivas para a Geolingüística no Brasil, realizado na cidade de Salvador - BA, em 1996, representantes das Universidades Federais da Bahia, da Paraíba, de Juiz de Fora, do Rio Grande do Sul e da Universidade Estadual de Londrina ${ }^{1}$ constituíram um Comitê Nacional para dirigir os trabalhos voltados para verificar as diferenças léxico-semânticas, investigar os aspectos fonético-fonológicos, morfossintáticos e prosódicos no português brasileiro, na tentativa de delimitar os contornos, ainda que tênues, dos dialetos ou falares nas diferentes áreas do Brasil. A primeira preocupação foi incluir no Comitê pesquisadores que tivessem consciência da real dimensão de um trabalho dessa natureza para que o projeto não se perdesse no caminho. Assim, foram designados autores de atlas já publicados: Bahia, Minas Gerais, Paraíba, Sergipe e Paraná e um representante de atlas em andamento, na época, o Atlas Linguístico e Etnográfico da Região Sul (ALERS). Cada representante passou a ser designado Diretor científico com a atribuição de um número de estados para coordenar. Mais tarde com a publicação do ALERS, uma pesquisadora do Atlas Linguístico do Mato Grosso do Sul passou a integrar

UFBA - Profa. Dra. Suzana Alice Marcelino da Silva Cardoso e Profa. Dra. Jacyra Andrade Mota; UFPB - Profa. Dra. Maria do Socorro Silva de Aragão; UFJF - Prof. Dr. Mário Roberto L. Zágari; UFRGS - Prof. Dr. Walter Koch; UEL - Profa. Dra. Vanderci de Andrade Aguilera. 
o Comitê Nacional como representante de atlas em andamento. Como é natural, o tempo e as circunstâncias foram demandando alterações na equipe diretora.

Além da Diretora-Presidente, da Diretora Executiva e dos Diretores Científicos, o Projeto conta com a equipe de Entrevistadores, responsável pela aplicação dos Questionários in loco. Sobre a preparação dos entrevistadores é importante sinalizar para a exaustão do treinamento para a captação dos dados, que foi uma constante desde o Workshop sobre técnicas e métodos de trabalho de campo para a preparação de inquiridores para o Atlas Lingüístico do Brasil-ALiB - realizado em Salvador - Bahia, nos dias 06 a 10 de setembro de 1999 e uma das tônicas das discussões em diversas outras reuniões do Comitê Nacional. A preocupação com a forma adequada na condução do inquérito, os procedimentos metodológicos e os problemas arrolados por Labov (1972) tornaram-se tema constante. A constituição do corpus do ALiB, embora ainda em construção, já permite que sejam feitas análises sobre o português falado no Brasil. Até o final do mês de março de 2012 já estava concluída a coleta de dados em 232 localidades do Brasil, correspondendo a 92,8\% do total da rede de pontos, o que representava 1.028 informantes entrevistados, ou 93,5\% do total de inquéritos.

Outra equipe considerada de suma importância para o avanço dos trabalhos do ALiB é a dos transcritores e revisores das entrevistas gravadas no campo. Trata-se de um grupo de bolsistas de Iniciação Científica que tem a incumbência de executar e manter as cópias de segurança, seja nos bancos de dados regional e nacional, seja sob a forma de arquivo sonoro em ambas as instâncias. Além do registro e arquivamento das entrevistas e cópias, é a equipe que transcreve grafemática e foneticamente os dados coletados, sob a supervisão do Diretor Científico.

De posse do material coletado, transcrito e revisado, duas outras equipes entram em cena: a dos informáticos, na alimentação do Banco de dados central, e a dos cartógrafos, na elaboração das cartas experimentais e definitivas, ambas sediadas na UFBA.

Sobre a disseminação dos resultados parciais, inicialmente direcionou-se para a descrição e análise da metodologia adotada pelo projeto. Na sequência, voltouse para o significativo volume de trabalhos sobre as entrevistas experimentais realizado por discentes de graduação (voluntários ou bolsistas da Iniciação Científica), de pós-graduação, e por docentes.

Passados 15 anos de instauração do projeto, outros trabalhos, agora com os dados dos inquéritos definitivos nas capitais e no interior, passam a compor o quadro da disseminação dos estudos realizados por esses pesquisadores. Somamse a estes nove publicações:

i) inicialmente, Aguilera (1998), verificando que não havia uma obra específica que proporcionasse ao público uma visão do conjunto dos trabalhos na área, reúne 
17 pesquisadores, nove dos quais participaram da elaboração de Atlas estaduais, e organiza a obra A geolingüística no Brasil: caminhos e perspectivas, que faz uma retomada da Dialetologia sob o método geolinguístico no país, além de apresentar dados e discussões sobre a metodologia adotada pelo projeto ALiB. Cardoso, no prefácio da obra, discorre:

A ideia de uma publicação mostrando os caminhos trilhados pela Geolinguística no Brasil (...) vem em boa hora. Primeiramente, porque um final de milênio sempre nos inspira e sugere um balanço, uma tomada de posição diante da história, uma visão crítica sobre o que se tem construído com projeção dos caminhos a percorrer. Em segundo lugar, porque a Dialectologia no Brasil vem passando por um processo de expansão, quando se amplia a produção de dissertações de Mestrado e teses de Doutorado na área e surgem novas incursões no campo da Geolinguística com a iniciativa de realização dos atlas linguísticos da Região Sul, de São Paulo, do Rio de Janeiro, de Mato Grosso do Sul, do Acre, do Pará, do Ceará e, mais recentemente, do Atlas Linguístico do Brasil. (CARDOSO, 1998, p.8).

ii) A publicação dos questionários do projeto é de suma importância para a Dialetologia nacional. Dos encontros promovidos pelo Comitê Nacional surgiram contribuições para o aperfeiçoamento dos questionários utilizados no trabalho de campo por meio dos três instrumentos de coleta de dados: o Questionário FonéticoFonológico (QFF), composto de 159 questões; o Questionário Semântico-Lexical (OLS), com 202 questões, e o Questionário Morfossintático (OMS), com 49 perguntas. Duas versões preliminares (publicadas em 1998 e 2000) foram testadas em diversos inquéritos experimentais e analisadas nos encontros nacionais, chegando à versão definitiva publicada em 2001 (COMITÊ NACIONAL DO ALiB, 2001).

iii) Decorridos sete anos dessa publicação, e já com a edição esgotada, Aguilera retoma a obra de 1998 e recorre aos novos geolinguistas brasileiros para organizar uma nova versão (AGUILERA, 2005a) acreditando que, entre 1991 (ano da publicação de A geografia linguística no Brasil, por Brandão) e 2005, devido à ampliação do campo dos referidos estudos, seria preciso voltar os olhos para a atualização dos dados e oferecer à academia uma obra que espelhasse os avanços da geolinguística nos últimos anos. Assim, A geolingüística no Brasil: trilhas seguidas e caminhos a percorrer (AGUILERA, 2005) acrescenta àqueles textos mais uma dezena de outros para informar sobre os novos atlas publicados e em andamento, mas principalmente para mostrar as novas diretrizes da Geolinguística no Brasil que, seguindo a tendência mundial e certamente influenciados pela metodologia adotada para o ALiB, associa dados diatópicos a diastráticos na feitura de atlas. 
(iv) e (v) A quarta e quinta obra que expõem os primeiros passos do ALiB são os Documentos I (AGUILERA; MOTA; MILANI, 2004) e Documentos II (MOTA; CARDOSO, 2006) que reúnem textos fundamentais para o entendimento do Projeto e para a compreensão da dimensão de que se reveste a pesquisa que desenvolve.

(vi) A sexta obra, Dos sons às palavras: nas trilhas da língua portuguesa (RIBEIRO; COSTA; CARDOSO, 2009), organizada em homenagem à Dr. Jacyra de Andrade Mota, Diretora Executiva do Projeto, trata da variação do português em seus diversos aspectos, focalizando, igualmente, resultados parciais do ALiB.

(vii) A sétima obra, Pelos caminhos da Dialetologia e da Sociolinguística: entrelaçando saberes e vidas (RAMOS; BEZERRA; ROCHA; OLIVEIRA; RAZKY, 2010), livro em homenagem à Dr. ${ }^{a}$ Maria do Socorro Aragão, Diretora Científica do ALiB, coordenadora regional em parte do Nordeste brasileiro, traz, além de estudos de renomados linguistas do Brasil, do Uruguai e de Portugal, artigos voltados para resultados parciais do ALiB.

(viii) A oitava publicação, Geolinguística: tradição e modernidade, da Diretora Presidente do ALiB (CARDOSO, 2010), retoma criticamente os procedimentos metodológicos adotados pelos vários atlas estaduais brasileiros e faz um balanço da Geolinguística no Brasil e em Portugal.

(ix) A Jornada dos Dicionários, evento tradicional e de alcance internacional, discute, com profundidade, temáticas relacionadas à Lexicografia e aos Dicionários. Em sua última edição, realizada em 2010, nos domínios da Universidade Federal da Bahia, foram três dias de discussões profícuas entre pesquisadores brasileiros e franceses sobre as temáticas da construção dos dicionários e da relação das obras lexicográficas com os estudos geolinguísticos. A nona publicação do projeto, a obra Os dicionários: fontes, métodos e novas tecnologias, organizada por Cardoso e Mota, diretoras do ALiB, e Salah Mejri (2011), diretor do LDI (Laboratoire Lexiques, Dictionnaires, Informatique), da Universidade Paris 13, é o fruto destas discussões e os artigos aí contidos ilustram a preocupação em concatenar os estudos das diversas áreas em prol do tratamento informatizado do léxico do projeto ALiB.

Além desses, há dezenas de artigos inseridos em obras nacionais e estrangeiras escritos por pesquisadores do ALiB, sobre aspectos léxico-semânticolexicográficos, fonético-fonológicos, morfossintáticos e metalinguísticos. Alguns deles abordam esses aspectos sob a ótica histórico-crítica da evolução do ALiB, conforme descrevemos nas seções seguintes. 


\section{O ALiB e a Iniciação Científica}

A formação de novos pesquisadores foi uma das metas priorizadas desde os primeiros momentos de vigência do ALiB, seja pela necessidade de contar com colaboradores jovens para a gigantesca tarefa de transcrição ${ }^{2}$, revisão e armazenamento de dados, seja pela urgência de criar e manter a mentalidade dialetológica da qual se ressentiram os pesquisadores que nos antecederam, como Nascentes e Silva Neto, que atribuíam à ausência dessa mentalidade a principal dificuldade para elaborar um atlas linguístico do país, não obstante outros empecilhos, como a grande extensão territorial e a ausência de apoio governamental.

Até o momento, registram-se 125 trabalhos realizados pelos alunos de IC orientados pelos diversos Diretores Científicos, que utilizaram como corpus os dados tanto das capitais, como do interior de um estado ou de uma região, e foram apresentados sob a forma de resumos, resumos ampliados, artigos em anais, relatórios parciais ou finais de pesquisa para os órgãos mantenedores da bolsa de IC, além da apresentação oral ou sob a forma de pôsteres em eventos de várias naturezas.

Desses 125 trabalhos de IC, 49 têm como objeto de estudo a variação lexical em torno das respostas dadas a questões de algumas áreas semânticas, como fenômenos atmosféricos (arco-íris, orvalho, sereno; nevoeiro, cerração, neblina), atividades agropastoris (tangerina, mexerica; penca de bananas; banana dupla, gêmeas; parte terminal da inflorescência da bananeira, umbigo, coração; mandioca, aipim), fauna (urubu, corvo; gambá), corpo humano (pálpebras, capela do olho; pomo-de-adão, gogó), convívio e comportamento social (pessoa pouco inteligente; assassino pago; marido enganado; prostituta; toco de cigarro), religião e crenças (diabo), jogos e diversões infantis (cambalhota, bolinha de gude; papagaio de papel, pipa; amarelinha), habitação (vaso sanitário), alimentação e cozinha.

Na sequência, 46 trabalhos versam sobre fenômenos fonéticos, como o /s/ em coda silábica interna ou externa, como em festa, costas, fósforo, casca; a monotongação de ei>e, de ai>a, de ou>0, como em travesseiro, torneira, caixa, tesoura, a ditongação de vogais finais seguidas de /s/, como em luz, paz, arroz; alternância de /v/ > /b/ e vice-versa, como em varrer>barrer, assobio>assovio, travesseiro>trabissero; o /r/ em início de sílaba ou palavra, como em varrer, terreno, rosa, arroz; a alternância de qüe/que, qüi/qui, qua/ca, entre outros. As regionais do Paraná e do Mato Grosso do Sul, em duas oportunidades, recolheram todo esse material e o publicaram em forma de CD para que não se perdesse o registro dessa importante etapa do Projeto ALiB na formação de novos pesquisadores (ISQUERDO; ALTINO; AGUILERA, 2009, 2012).

É bom lembrar que, ao final, serão 1.100 entrevistas gravadas, cada qual com a duração média de 2h30min, transcritas e revisadas. 
Os trabalhos sobre o Questionário Morfossintático, em número de seis, dizem respeito, sobretudo, à variação de nós e a gente; de ter e haver, no sentido de existir, junto aos falantes das capitais investigadas.

As discussões sobre a Metodologia adotada pelo ALiB resultaram em 18 trabalhos desenvolvidos por graduandos de Letras da UFBA, UFMS, UFPA, UFSC e UEL. Além desses, três deles exploraram as Questões de Metalinguística e os demais se ativeram à prosódia e à análise dos dados fonéticos e lexicais ligados à história social do povoamento das várias regiões do Brasil, com ênfase no papel disseminador da variante provavelmente usada pelos bandeirantes e, posteriormente, pelos tropeiros, que deu origem aos traços caipiras na fala do interior de São Paulo e do Paraná, do sul de Minas Gerais, Mato Grosso do Sul, parte do Mato Grosso, de Goiânia, de Santa Catarina e do Rio Grande do Sul.

O gráfico 1 mostra a distribuição dos trabalhos de IC por área analisada:

\section{Gráfico 1 - Trabalhos de IC}

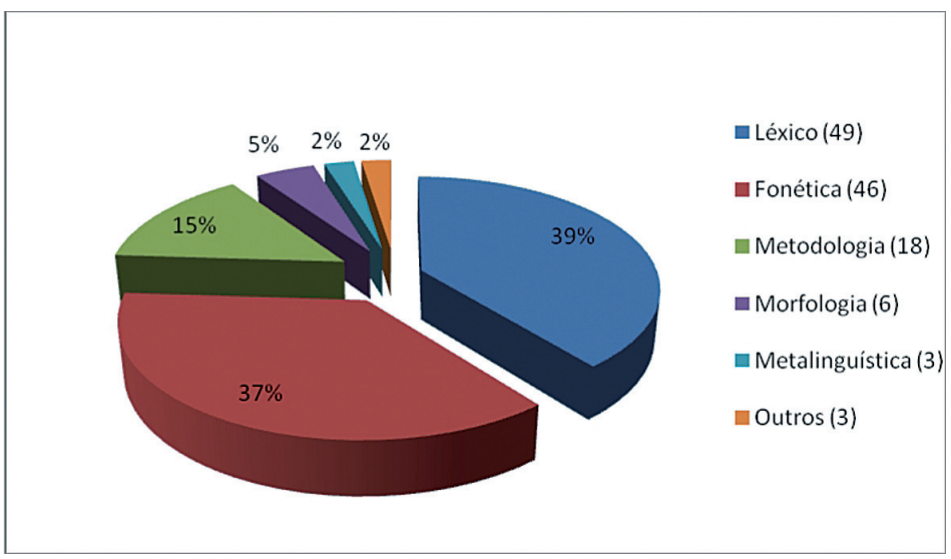

Fonte: Textos construídos com dados do ALiB entre 2003 e 2011.

Muitos dos trabalhos desenvolvidos como projetos de IC estão auxiliando na discussão da divisão dialetal do português brasileiro proposta por Nascentes, em 1953, que divide o país em dois grupos de falares: o do Norte e o do Sul. Neste último estão inseridos os falares: Baiano, Fluminense, Mineiro e Sulista; enquanto naquele, os falares Amazônico e Nordestino. Para Nascentes havia, ainda, uma terceira área denominada de território incaracterístico.

Como ilustração dos inúmeros trabalhos de IC, Romano, em co-autoria com Aguilera (2009), em artigo de natureza geolinguística e lexicológica, chega às seguintes conclusões acerca da distribuição diatópica das variantes, coletadas nas capitais, para a questão 039 sobre a fruta da família da laranja que se descasca com as unhas: 
A análise das variantes para a questão 039, apresentadas nas 25 capitais, permite tecer as seguintes considerações:

(i) tangerina é a forma mais produtiva e mais frequente que se distribui diatopicamente por quase todas as regiões, embora não apareça como a primeira resposta em algumas delas, sobretudo em capitais onde prevalecem as formas dialetais, como tanja, bergamota, laranja-cravo e mimosa;

(ii) as variantes se distribuem de modo muito próximo ao que preconizou Nascentes (1958) ao propor a divisão dialetal do Brasil em falares do Norte e do Sul, de modo que tangerina se realiza como variante mais produtiva no Norte e mexerica no Sul/Sudeste/Centro-Oeste;

(iii) nem todas as variantes regionais constam dos seis dicionários consultados, como ocorre com laranja-cravo, poncã, mimosa e tanja;

(iv) os dicionários elegem a forma laranja + a variante como a forma padrão: laranja-tangerina, laranja-mimosa, laranja-cravo que depois, na linguagem oral e informal, se reduz ao segundo termo;

(v) a maioria dos lexicógrafos faz referência às variantes regionais, embora não as localizem nas respectivas regiões;

(vi) dicionários mais antigos não trazem as formas regionais, como mimosa, que vão aparecer somente nas edições mais recentes como Houaiss (2001) e Ferreira (2004);

(vii) destaca-se a importância dos estudos geolinguísticos como fonte segura para os lexicógrafos. (ROMANO; AGUILERA, 2009, p.157).

Os autores ilustram com uma carta experimental (figura 1) que traz as formas predominantes em cada uma das 25 capitais.

\section{Figura 1 - Carta experimental (preparada ad-hoc) sobre as variantes de tangerina registradas nas 25 capitais}

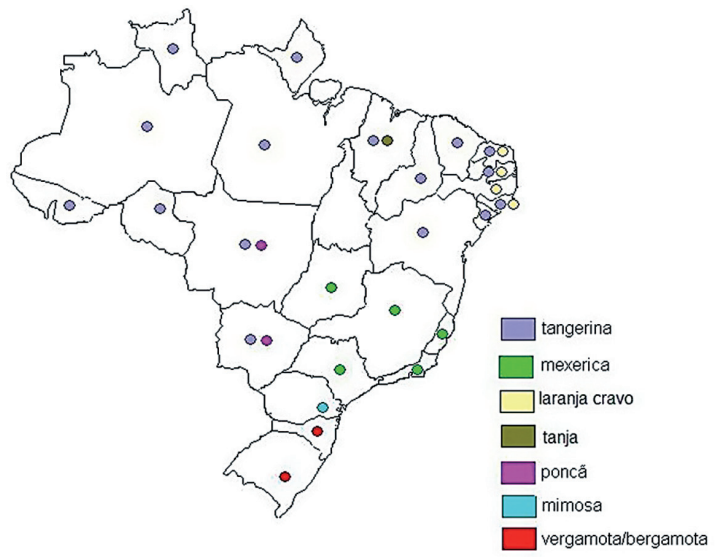

Fonte: Romano e Aguilera (2009). 


\section{A produção no nível da Pós-Graduação Lato e Stricto Sensu}

Mais de uma dezena de trabalhos em nível de pós-graduação stricto sensu foram, ou estão sendo, desenvolvidos pelas diversas IES do país. São estudos no âmbito da fonética-fonologia, da morfossintaxe e do léxico, como sintetiza o gráfico 2:

\section{Gráfico 2 - Síntese da produção na pós-graduação lato e stricto sensu com dados do ALiB}

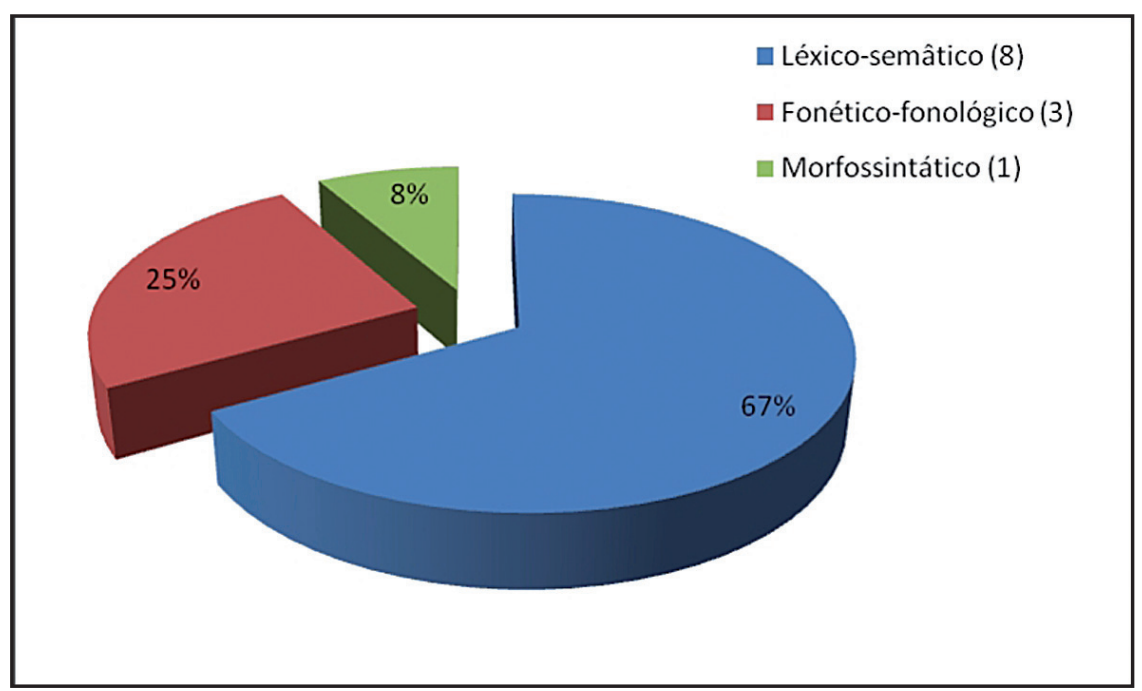

Fonte: Banco de dados do ALiB.

O levantamento feito a partir dos dados semântico-lexicais permite organizar a apresentação do universo vocabular para as respostas obtidas às questões, segundo alguns critérios, como: arcaísmos, brasileirismos, criações neológicas, variações no âmbito da diatopia, dialetismos, formação dos vocábulos, africanismos, vestígios das línguas indígenas; coletados nas entrevistas e que poderão ser apresentados nas cartas semântico-lexicais.

Dentre os estudos, em nível de Mestrado que tratam desta área, destacamse os trabalhos apresentados na tabela 1: 
Tabela 1 - Dissertações desenvolvidas com os dados do projeto ALiB

\begin{tabular}{|c|c|c|c|}
\hline $\begin{array}{l}\text { Título } \\
\end{array}$ & Autor & Instituição & Ano \\
\hline $\begin{array}{l}\text { O campo léxico-semântico corpo } \\
\text { humano no português do Brasil }\end{array}$ & $\begin{array}{l}\text { Daiane Cunha dos } \\
\text { Santos }\end{array}$ & UFBA & 2008 \\
\hline $\begin{array}{l}\text { Variantes lexicais no campo semântico } \\
\text { da alimentação e cozinha no Brasil }\end{array}$ & Vanessa Yida & UEL & 2009 \\
\hline $\begin{array}{l}\text { Em busca de vestígios das línguas } \\
\text { indígenas no português falado nas } \\
\text { regiões Norte e Centro-Oeste do Brasil: } \\
\text { um estudo geolinguístico }\end{array}$ & $\begin{array}{l}\text { Daniela de Souza Silva } \\
\text { Costa }\end{array}$ & UFMS & $\begin{array}{l}\text { Início } \\
2010\end{array}$ \\
\hline $\begin{array}{l}\text { Um estudo do vocabulário rural na } \\
\text { região Centro-Oeste: perspectiva } \\
\text { geolinguística }\end{array}$ & Luciene Gomes Freitas & UFMS & $\begin{array}{l}\text { Início } \\
2010\end{array}$ \\
\hline $\begin{array}{l}\text { Tabus linguísticos na fala dos habitantes } \\
\text { das capitais brasileiras documentados } \\
\text { pelo Projeto ALiB }\end{array}$ & $\begin{array}{l}\text { Vanessa Cristina } \\
\text { Martins Bencke }\end{array}$ & UFMS & $\begin{array}{l}\text { Início } \\
2010\end{array}$ \\
\hline $\begin{array}{l}\text { Áreas dialetais do Brasil: em busca do } \\
\text { falar amazônico }\end{array}$ & $\begin{array}{l}\text { Danyelle de Almeida } \\
\text { Saraiva }\end{array}$ & UFMS & $\begin{array}{l}\text { Início } \\
2010\end{array}$ \\
\hline
\end{tabular}

Fonte: Dados extraídos do Currículo Lattes de cada autor.

Os estudos com o léxico, registrado nas entrevistas do projeto, rendem ainda dois trabalhos em nível de doutorado. São as teses Áreas lexicais do português brasileiro, recentemente defendida, e O léxico brasileiro: confronto entre áreas segundo os dados do projeto ALiB, ambas desenvolvidas na Universidade Federal da Bahia, sede do projeto, respectivamente por Márcia Verônica R. de Macêdo e Genivaldo da Conceição Oliveira. Ambas buscam delimitar as áreas dialetais dos falares brasileiros.

Os trabalhos sobre a fonética e fonologia do português brasileiro demonstram que este é um campo fértil para o desenvolvimento de dissertações e teses. A exemplo disto, temos os estudos em nível de mestrado e doutorado listados neste artigo.

A dissertação de Hélen Cristina da Silva, desenvolvida na Universidade Estadual de Londrina - UEL, sob o título de $O / R /$ caipira no triângulo mineiro: um estudo dialetológico e de atitudes linguísticas (2012), situa-se no âmbito da Dialetologia Pluridimensional e da Sociolinguística, e utilizou três corpora distintos: os dados do EALMG, os do ALiB coletados nas cidades de Campina Verde e Uberlândia e os resultantes da pesquisa de campo realizada pela mestranda, com os objetivos de apresentar e discutir a distribuição espácio-social do /r/ caipira nas cidades de Campina Verde, Frutal, Ituiutaba, Iturama, Prata e Uberlândia, situadas no Triângulo Mineiro, analisada em tempo aparente e tempo real. Além de verificar a provável existência de mudança em curso refletida na diminuição da área do /r/ retroflexo, a mestranda buscou averiguar aspectos extralinguísticos que possam influenciar nesse processo.

O estudo intitulado Variação fonética dos ditongos /ey/ e /ow/ nas capitais do Norte Nordeste do Brasil, desenvolvido por Williane Brasil dos Santos na 
Universidade Federal do Pará - UFPA (2012) propôs verificar a manutenção e/ ou apagamento dos ditongos na língua falada em algumas capitais do país, averiguando, por meio da metodologia da Sociolinguística e da Dialetologia Pluridimensional, quais aspectos interferem na realização/apagamento desses ditongos. Para essa pesquisa, foram utilizados os 120 inquéritos dos informantes (8 para cada localidade) das seguintes capitais: Macapá, Boa Vista, Manaus, Belém, Rio Branco e Porto Velho, na região Norte; e Salvador, São Luis, Teresina, Fortaleza, Natal, João Pessoa, Recife, Maceió e Aracaju, na região Nordeste.

A tese de doutoramento de Silvana Ribeiro, Regiões dialetais do Brasil: em busca do falar baiano, na trilha de Antenor Nascentes, recentemente defendida na Universidade Federal da Bahia, tem por objetivo examinar a vitalidade da divisão dialetal do Brasil proposta por Antenor Nascentes (1952) a partir da distribuição dos nomes para brinquedos e brincadeiras infantis. A tese de Ribeiro revisita o estudo de Nascentes e discute a pertinência dos limites estabelecidos em face da realidade linguística atual do país. Para a pesquisa foram utilizadas as 72 entrevistas do projeto ALiB nas 9 capitais do Nordeste.

No âmbito da morfossintaxe, o Projeto conta com a dissertação de mestrado VOCÊ ou TU? Nordeste versus Sul: o tratamento do interlocutor no português do Brasil, a partir dos dados do Projeto ALiB, desenvolvida na Universidade Federal da Bahia por Viviane Gomes de Deus. Trata-se de um estudo que buscou verificar a manutenção ou a substituição do pronome pessoal reto tu pelo pronome de tratamento você, além de analisar os aspectos linguísticos e/ou extralinguísticos que interferem na seleção dos pronomes pelos falantes.

Os estudos elencados acima demonstram a importância do projeto ALiB na formação acadêmica de novos pesquisadores nas diferentes áreas do saber linguístico. Fica evidente, ainda, a abrangência do projeto, que mobiliza pesquisadores de diversas regiões do país, como demonstra o gráfico 3.

\section{Gráfico 3 - Produção de trabalhos acadêmicos na pós- graduação, com dados do ALiB, por IES}

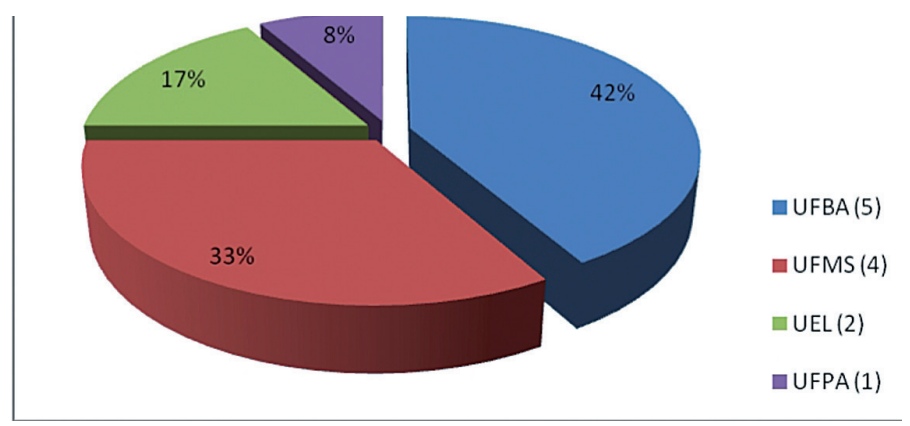

Fonte: Banco de dados do ALiB. 


\section{A atuação dos coordenadores regionais e diretores científicos}

Como uma nova fase da Dialetologia brasileira, a retomada de um projeto de atlas linguístico nacional, em 1996, revitaliza a área e favorece a instalação de uma "mentalidade dialetológica" preconizada por Silva Neto (1957), já mencionada aqui, inaugurando uma nova etapa dos estudos geolinguísticos. Esse $4^{\circ}$ período já proposto por vários pesquisadores ${ }^{3}$ confirma-se pelas inovações metodológicas adotadas, pela envergadura do projeto ALiB, pela disseminação da área de pesquisa junto aos órgãos de fomento e às instituições de ensino superior (IES). Diante deste cenário, vê-se a profícua produção acadêmica do Comitê Nacional. São inúmeros os estudos publicados nos eventos e revistas em nível nacional e internacional e capítulos de livros como demonstramos no quadro 1 :

\section{Quadro 1 - Produção acadêmica por tipo de publicação nacional e internacional}

\begin{tabular}{|l|c|c|}
\hline \multicolumn{1}{|c|}{ Tipo de publicação } & Número de publicações & \% \\
\hline Nacional: revistas e anais & 56 & 70 \\
\hline Capítulos de livros & 12 & 15 \\
\hline Internacional: anais, revistas e capítulos de livros & 12 & 15 \\
\hline Total & 80 & 100 \\
\hline
\end{tabular}

Fonte: Elaboração própria.

Quanto à temática dos trabalhos, inicialmente foi necessário explicitar e divulgar as intenções do grupo do ALiB quanto à retomada do projeto já preconizado em 1952, com a publicação do Decreto 30.643, que previa a elaboração de um atlas linguístico em que os falares brasileiros fossem identificados.

Nos anos iniciais do projeto ALiB, a discussão da metodologia era a constante preocupação e disseminar as bases de tão grande empreitada passou a ser a tônica dos trabalhos. Dos 56 estudos publicados em anais e revistas nacionais, pode-se observar a concentração de artigos que descrevem e explicam o funcionamento do projeto e, ainda, discutem a metodologia aplicada. É o que se observa no gráfico 4:

A periodização da Dialetologia brasileira foi apresentada por Nascentes em 1952, oportunidade em que o autor descreve as duas primeiras fases retomadas por Mota e Cardoso (2006). 


\section{Gráfico 4 - Distribuição por temas das produções em revistas e anais nacionais}

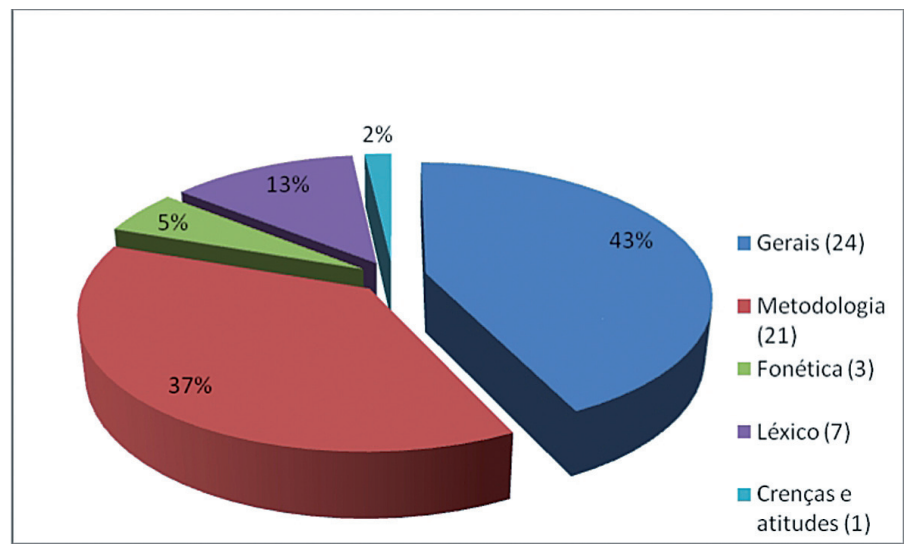

Fonte: Banco de dados do ALiB.

Uma vez implantado o Projeto, a próxima etapa seria a de torná-lo conhecido do grande público acadêmico. Inicia-se, dessa forma, a etapa de divulgação das diretrizes que iriam nortear o trabalho de campo da equipe: como estava sendo planejada e concretizada a formação dos inquiridores, transcritores e revisores, basilares para a composição do banco de dados. Cabe aqui salientar o papel importante do ALiB na formação da mentalidade dialetológica e no estabelecimento e discussão das diretrizes norteadoras do trabalho do geolinguista no Brasil.

Não há como negar que o projeto ALiB é um divisor de águas para a Geolinguística no país. A partir da disseminação da metodologia, muitos trabalhos passaram a utilizar os seus questionários, os critérios de seleção de informantes e a rede de pontos, para citar os mais evidentes, em seus estudos. Esta popularização se dá por meio das publicações que tratam exaustivamente do projeto, exibem as bases e estratégias de ação. Como exemplos, listam-se os artigos de Mota e Cardoso (1998), Aguilera (2001), Isquerdo (2004), Aragão (2004) e Cardoso (2009a).

Uma das inovações do Projeto, e que recebeu atenção especial, foi a elaboração e posterior publicação do instrumento de pesquisa. A prerrogativa da fase de implementação recaiu sobre o instrumento de coleta de dados, elaborando-se questionários que pudessem refletir os objetivos do Projeto, indicando com clareza as noções cujas denominações se pretendem extrair dos informantes, os traços fonéticos e prosódicos recorrentes em cada região estudada. A posterior disseminação desta etapa metodológica foi campo frutífero para a elaboração de artigos. É o que se pode constatar nos artigos de Cardoso (1999), Mota e Cardoso (1999), Aguilera (1999) e Mota (1999), utilizados aqui como amostragem. 
Cardoso (1999) discute a importância de ajustar o instrumento de coleta de dados à realidade cultural dos informantes. Devido à dimensão continental e à diversidade cultural bastante saliente no Brasil, haja vista os costumes do norte comparados aos do sul, por exemplo, se fez necessária uma reflexão cuidadosa sobre a pesquisa de campo para que se pudesse abranger todas as regiões. Da mesma forma, os trabalhos de Aguilera (1999) e Mota (1999) demonstram a preocupação da equipe em compor questionários adequados aos fenômenos pesquisados.

A produção científica dos coordenadores regionais e diretores do projeto ALiB abrange, também, a publicação de capítulos de livros, organizados em diversas instituições no país. Esses estudos versam sobre a metodologia adotada (50\% dos trabalhos), a fonética (25\%), o léxico (17\%) e crenças e atitudes linguísticas (8\%), e estão presentes nas publicações de oito estados brasileiros (Goiás, Paraná, São Paulo, Rio de Janeiro, Minas Gerais, Mato Grosso, Mato Grosso do Sul e Bahia). A título de exemplos, citamos: (i) sobre a metodologia: Aguilera (2002); (ii) sobre léxico: Cardoso (2003), Aguilera (2005b), Aguilera (2010); (iii) sobre fonética: Mota (2008); (iv) sobre crenças e atitudes: Aguilera (2008).

O projeto ALiB está presente, ainda, nas publicações de nível internacional. A coordenação regional e os diretores científicos, até o momento, publicaram 12 artigos em anais de congressos fora do país e em coletâneas que homenageiam personalidades da área. Esses artigos estão levando o Projeto para discussões em novas esferas do saber e possibilitando alianças para o melhor aproveitamento dos dados coletados. Sendo assim, artigos como "La dialectologie au Brésil. Aperçue historique e bilan actuel" (CARDOSO, 2002); "O Projeto ALiB - das origens ao momento atual" (CARDOSO, 2008); "A rede de pontos: uma reflexão sobre a história social das capitais de estado que integram o Projeto ALiB" (ISQUERDO, 2008) e "Revisitando os conceitos de rural e urbano no português do Brasil: contribuições do Projeto ALiB” (ISQUERDO, 2010) levam para a discussão dos colegas estrangeiros a metodologia empregada e já bastante veiculada nos meios acadêmicos nacionais.

Os capítulos de livros publicados no exterior encerram a exposição das publicações sobre o ALiB. São produções científicas que tratam da questão metodológica e trazem alguns dos primeiros resultados das análises. É o que se verifica nas publicações de Cardoso e Mota (2003), Mota e Souza (2009), Aguilera (2010) e Mota e Cardoso (2011).

\section{Conclusões}

Neste artigo procurou-se demonstrar, em linhas gerais, a trajetória percorrida pelo ALiB em seus 15 anos de vigência. Para isso, apresentou-se a constituição da equipe de pesquisadores que atuam nas diversas etapas e funções do Projeto, 
seguindo-se os comentários sobre a ampla produção discente no que se refere aos trabalhos de IC, desenvolvidos sob a orientação dos Diretores Científicos que compõem o Comitê Nacional. Na terceira parte, relatam-se os trabalhos de pósgraduação lato e stricto sensu, também sob a orientação dos Diretores Científicos em cada Regional, que aprofundam os temas abordados pelos graduandos. $\mathrm{Na}$ quarta e última parte, discorre-se sobre os trabalhos dos docentes pesquisadores. Embora acredite-se não estar completa a relação das pesquisas realizadas nos diferentes estratos do Comitê, este é um retrato do que se fez para e pelo ALiB nesses 15 anos. A meta é, dentro de pouco tempo, trazer ao público os primeiros volumes do tão almejado Atlas Linguístico do Brasil.

AGUILERA, V. de A.; ALTINO, F. C. For a Multidimensional Atlas: Research and Researchers. Alfa, São Paulo, v.56, n.3, p.861-879, 2012.

- ABSTRACT: This article aims at presenting to the scientific community a report on the activities of the Project Atlas Linguístico do Brasil (ALiB-Lingusitic Atlas of Brazil) concerning the constitution of new researchers and, at the same time, to demonstrate what the Central Committee team has produced since the beginning of this century. We divided the text into four sections: (i) the constitution of the team of investigators that deals with the formation of the National Committee and the attributions of each of its members; (ii) students' production in Scientific Initiation Projects developed in the several ALiB branches; (iii) the postgraduation students' production tutored by the scientific directors; and (iv) the production of the coordinators and scientific directors. The results indicate the diversity of theoreticalmethodological perspectives in the approach of phenomena related to phonetic, lexical and morphological variation, among others, and also indicate the possibility of associating some aspects of linguistic variation found by ALiB to the proposal by Nascentes (1953).

- KEYWORDS: Linguistic Atlas of Brazil. Constitution of the National Committee. Scientific Production. Dialectal Division of Brazil.

\section{REFERÊNCIAS}

AGUILERA, V. A. Arcaização, mudança e resistência lexicais em atlas linguísticos brasileiros: o rural e o urbano. In: DÖLL, C. et al. (Org.). De arte grammatica: Festschrift für Eberhard Gärtner zu seinem 65. Geburtstag. Frankfurt am Main: Valentia, 2010. p.19-32.

. Estudos dialetológicos no Paraná: caminhos e perspectivas. In: GÄRTNER, E.; HUNDT, C.; SCHÖNBERGER, A. (Org.). Estudos de geolingüística do português americano. Frankfurt am Main:Valentia, 2009.

Crenças e atitudes lingüísticas: quem fala a língua brasileira? In: RONCARATI, C.; ABRAÇADO, J. (Org.). Português brasileiro II: contato lingüístico, heterogeneidade e história. Niterói: Ed. da UFF, 2008. p.311-333. 
(Org.). A Geolingüística no Brasil: trilhas seguidas, caminhos a percorrer. Londrina: Ed. da UEL, 2005a.

. Léxico regional, léxico rural ou vocabulário de curiosidade? Um olhar sobre aspectos lexicais de Cuiabá. In: ALMEIDA, M. M. S.; COX, M. I. P. (Org.). Vozes cuiabanas: estudos lingüísticos em Mato Grosso. Cuiabá: Cathedral Publicações, 2005b. p.115-136.

. Caminhos da dialetologia: os Atlas lingüísticos do Brasil. In: HENRIQUES, C. C.; PEREIRA, M. T. G. (Org.). Língua e transdisciplinaridade: rumos, conexões, sentidos. São Paulo: Contexto, 2002. p.77-92.

Atlas Lingüísticos do Cone Sul: a caminhada do Atlas Lingüístico do Brasil. Revista de Letras, Curitiba, v.1, n.56, p.45-64, 2001.

. ALiB: considerações sobre o Questionário Léxico-semântico. A Cor das Letras, Feira de Santana, v.1, n.3, p.203-215, 1999.

(Org.). A geolingüística no Brasil: caminhos e perspectivas. Londrina: Ed. da UEL, 1998.

AGUILERA, V. A; MOTA, J. A.; MILANI, G. A. L. Documentos I: Projeto do Atlas Lingüístico do Brasil. Salvador: Ed. da UFBA, 2004.

ARAGÃO, M. S. S. Atlas Lingüístico do Brasil - Estado da Paraíba - ALiB-PB. Conceitos, João Pessoa, v.5, p.42-48, 2004.

BRANDÃO, S. F. A geografia linguística no Brasil. São Paulo: Ática, 1991.

CARDOSO, S. A. M. Geolinguística: tradição e modernidade. São Paulo: Parábola, 2010.

. Projeto Atlas Linguístico do Brasil-Projeto ALiB: descrição e estágio atual. Revistada ABRALIN, Brasília, v.8, p.185-198, 2009a.

Projeto Atlas Linguístico do Brasil (Projeto ALiB): uma resposta da geolinguística ao conhecimento do português brasileiro. In: GÄRTNER, E; SCHÖNBERGER, A. (Org.). Estudos sobre o português brasileiro. Frankfurt am Main:Valentia, 2009b. v. VIII. p.153-161.

O Projeto ALiB: das origens ao momento atual. In: CONGRESO INTERNACIONAL DE LA ASOCIACIÓN DE LINGÜÍSTICA Y FILOLOGÍA DE AMÉRICA LATINA, 15., 2008, Montevidéu. Anais... Montevidéo: ALFAL, 2008. p.397-422.

Arco-íris, estrela cadente e via láctea: que traçados fazem do português do Brasil? Revista Portuguesa de Filologia, Coimbra, v.24, n.1, p.77-100, 2003. 
La dialectologie au Brésil. Aperçue historique er bilan actuel. Géolinguistique, Grenoble, v.2, p.197-229, 2002.

. Geolingüística: convergências e divergências na coleta de dados. Estudos Lingüísticos e Literários, Salvador, v.23/24, p.143-153, 1999.

. Prefácio. In:AGUILERA, V. A. (Org.). A Geolingüística no Brasil: caminhos e perspectivas. Londrina: Ed. da UEL, 1998. p.8.

CARDOSO, S. A. M; MOTA, J. A. A geolinguística no Brasil e o Projeto ALiB. Bollettino dell' Atlante Linguístico Italiano, Torino, III série, n.27, p.255-267, 2003.

CARDOSO, S. A. M.; MOTA, J. A.; MEJRI, S. (Org.). Os dicionários, fontes, métodos e novas tecnologias. Salvador:Vento Leste, 2011.

COMITÊ NACIONAL DO PROJETO ALiB. Questionários 2001. Londrina, Ed. da UEL, 2001.

ISQUERDO, A. N. Revisitando os conceitos de rural e urbano no português do Brasil: contribuições do Projeto ALiB. In: CONGRES INTERNATIONAL DE LINGUISTIQUE ET DE PHILOLOGIE ROMANES, 25., 2010, Innsbruck. Actes... Berlim: De Gruyter: 2010. p.137-146, v. IV.

A rede de pontos: uma reflexão sobre a história social das capitais de estado que integram o Projeto ALiB. In: CONGRESO INTERNACIONAL DE LA ASOCIACIÓN DE LINGÜÍSTICA Y FILOLOGÍA DE AMÉRICA LATINA, 15., 2008, Montevideo. Actas... Montevideo: Diretoria da ALFAL, 2008, p.1-22, v. I.

Projeto ALiB: veredas. Estudos Linguísticos, Campinas, v.33, p.1-6, 2004.

ISQUERDO, A. N; ALTINO, F. C.; AGUILERA, V. A. (Org.). Atlas Linguístico do Brasil: descrevendo a língua, formando jovens pesquisadores. Londrina: Ed. da UEL, 2012. v. 2.

Atlas Linguístico do Brasil: descrevendo a língua, formando jovens pesquisadores. Londrina: Ed. da UEL, 2009.

LABOV, W. Sociolinguistic patterns. Philadelphia: University of Pennsylvania Press, 1972.

MOTA, J. A. Como fala o nordestino: a variação fônica nos dados do Projeto Atlas Lingüístico do Brasil. In: LIMA-HERNANDES, M. C. et al. (Org.). A língua portuguesa no mundo. São Paulo: FFLCH-USP, 2008.

Atlas Lingüístico do Brasil: o questionário fonético-fonológico e o questionário morfossintático. A Cor das Letras, Feira de Santana, v.3, p.123-137, 1999. 
MOTA, J. A; CARDOSO, S. A. Variantes lexicais e estratificação social no português brasileiro: uma visão com base nos dados do Projeto Atlas Linguístico do Brasil. In: SILVA, A. S. da; TORRES, A.; GONÇALVES, M. (Org.). Línguas Pluricêntricas, variação linguística e dimensões sociocognitivas. Braga: Universidade Católica Portuguesa, 2011.

. Documentos II: projeto do Atlas Lingüístico do Brasil. Salvador: Quarteto, 2006.

. O Atlas Linguístico Galego e o Projeto Atlas Linguístico do Brasil: questões metodológicas. In: REI-DOVAL, G (Org.). A linguística galega desde além mar. Santiago de Compostela: Universidade de Santiago de Compostela, 1999.

. Um desafio: o Atlas Lingüístico do Brasil. Estudos Lingüísticos e Literários, Salvador, n.21-22, p.87-95, 1998.

MOTA, J. A.; SOUZA, L. N. Estudo de fatos fônicos em inquéritos experimentais do ALiB: o apagamento dos róticos em coda silábica. In: GÄRTNER, E.; HUNDT, C.; SCHÖNBERGER, A (Org.). Estudos sobre o português brasileiro. Frankfurt am Main:Valentia, 2009.

NASCENTES, A. O linguajar carioca. 2. ed. Rio de Janeiro: Organização Simões, 1953.

Études dialectologiques au Brésil. ORBIS - Bulletin Internacional de Documentation Linguistique, Louvain, Tome I, n. 1, 1952.

RAMOS, C. M. A. et al. Pelos caminhos da dialetologia e da sociolinguística: entrelaçando saberes e vidas. São Luís: Ed. da UFMA, 2010.

RIBEIRO, S. S. C.; COSTA, S. B. B.; CARDOSO, S. A. M. (Org.). Dos sons às palavras: nas trilhas da língua portuguesa. Salvador: Ed. da UFBA, 2009.

ROMANO, V. P.; AGUILERA, V. A. A distribuição diatópica das variantes para tangerina: um estudo geo-sociolinguístico. In: ISQUERDO, A. N.; ALTINO, F. C.; AGUILERA, V.A. (Org.). Atlas Linguístico do Brasil: descrevendo a língua, formando jovens pesquisadores. Londrina: Ed. da UEL, 2009. p.148-157.

SANTOS, W. B. dos. Variação fonética dos ditongos ley/ e /ow/ nas capitais do norte e nordeste do Brasil. 280f. 2012. Dissertação (Mestrado em Lingüística) Universidade Federal do Pará, Belém, 2012.

SILVA, H. C. O /R/ caipira no triângulo mineiro: um estudo dialetológico e de atitudes linguísticas. 186f. 2012. Dissertação (Mestrado em Estudos da Linguagem) - Universidade Estadual de Londrina, Londrina, 2012. 
SILVA NETO, S. da. Guia para estudos dialetológicos. Belém: Conselho Nacional de Pesquisa: Instituto Nacional da Amazônia, 1957.

THUN, H. La géographie linguistique romane à la fin du XX ${ }^{e}$ siècle. In: CONGRES INTERNATIONAL DE LINGUISTIOUE ET DE PHILOLOGIE ROMANES, 22., 1998, Bruxelles. ACTES... Tübingen: Niemeyer, 2000. p.367-388. v. III.

Recebido em março de 2012.

Aprovado em agosto de 2012. 